EarthArXiv coversheet for:

Wind tunnel tests inform Ammophila planting spacing for dune management

Bianca R. Charbonneau*1 and Brenda B. Casper ${ }^{1}$

${ }^{1}$ Biology Department, University of Pennsylvania, 433 South University Ave, 330A Leidy Labs, Philadelphia, PA 19104-4544

${ }^{*}$ Corresponding author: binoink@gmail.com (email) @thedunegoon (Twitter \& Instagram) www.thedunegoon.weebly.com (website)

This article is a postprint from Shore \& Beach, published by ASBPA. Shore \& Beach authors retain copyright over their work, and the journal also permits the distribution of typeset manuscripts (this was confirmed with the editor).

Shore \& Beach does not mint DOIs, therefore citation of this article should us the EarthArXiv $\mathrm{DOI}$ appended to the following citation:

Charbonneau BR and Casper BB (2018), Wind tunnel tests inform Ammophila planting spacing for dune management, Shore \& Beach, Vol. 86, No. 3, p37-46 <EarthArXiv DOI> 


\title{
Wind tunnel tests inform Ammophila planting spacing for dune management
}

\author{
By \\ Bianca Reo Charbonneau ${ }^{1}$ and Brenda Casper ${ }^{1}$ \\ ${ }^{1}$ Department of Biology, University of Pennsylvania, Philadelphia, PA 19104 \\ Contact: Bianca Reo Charbonneau \\ University of Pennsylvania, 330 Leidy Labs, 3740 Hamilton Walk, Philadelphia, PA 19104-6018 \\ Tel: (973) 879-2856 \\ E-mail: BCharbon@sas.upenn.edu
}

\begin{abstract}
Coastal dunes are invaluable natural resources that buffer upland areas. Vegetation is key in dune development and stabilization. Dunes form with sufficient wind, sand source, and obstruction; plants are the ideal obstruction. Storms often erode foredunes and coastal managers replant vegetation to re-establish the necessary obstruction for sand accretion and dune growth. We used a wind tunnel to examine the effect of planting density on bedform formation under constant $18.5 \mathrm{mph}(8.25 \mathrm{~m} / \mathrm{s})$ winds for $30 \mathrm{~min}$. We filled $1 \mathrm{~m} \times 1 \mathrm{~m} \times .3 \mathrm{~m}$ deep boxes with sand and then planted Ammophila breviligulata plugs in two densities commonly used in management, 12 inches (30.5 $\mathrm{cm})$ and 18 inches $(45.7 \mathrm{~cm})$ on center. Sand was supplied by a downwind 1-inch sand bed to mimic backshore transport. We measured the morphology of each plant and used a 3D sensor to record the topography of the bedforms that formed in association with each plant. The bedforms did not vary in volume or basal area as a function of planting density, but biomass was a significant predictor of volume, with larger plants producing larger bedforms. We observed all accretionary bedforms in our low-density treatment, but both erosion and accretion in the high-density treatments potentially due to an inaccurate measure of pre-experiment base height or interactions among neighbors causing greater turbulent kinetic energy with tighter spacing. Bedform height, accretionary or erosive, did not vary by density, row, plant width, or biomass. The bedform shape, measured as the length to width ratio did vary by density; plants in the low-density treatment, despite being morphologically the same, produced bedforms with longer tails. These differences are likely a function of wind backflow and plant interaction interrupting flow, both of which are reduced with a lower planting density. The bedforms created at the onset of planting are thought to carry over through the life of the dune, such that understanding how density affects bedform shape should be considered when making management decisions.
\end{abstract}

$\mathrm{N}$ atural or nature-based management solutions are the local and global answer to environmental issues (Feagin et al. 2010; Cohen-Shacham et al. 2016). Coastal dunes are no exception to this (Bridges et al. 2015), as governing bodies have long appreciated that vegetation increases the resiliency of dunes. Basing management decisions on this knowledge is not always possible as decisions can be a cultural, legal, safety, economic, aesthetic, and environmental balancing act (Elko et al. 2016). Today, both hard engineering and nature-based soft management solutions have been employed worldwide to stabilize coasts and protect infrastructure from storms, sea level rise, and coastal squeeze (Freestone and Nordstrom 2001; Harman et al.
2013; Charbonneau 2015). The effects of Superstorm Sandy (October 2012) demonstrated the advantages of dunes and vegetation stabilizing them for coastal protection (Barone et al. 2014; Feagin et al. 2015; Elko et al. 2016; Charbonneau et al. 2017), and dunes are now a preferred management option over hard engineering (Feagin et al. 2010; Charbonneau 2015).

Understanding the role of vegetation for dune building and stabilization is important for nature-based beach management. Dunes will form with a sand source, wind great enough to cause grain entrainment, and an obstruction to catch sand (i.e. plant, fencing, or wrack); plants are the ideal obstruction. Plant roots stabilize otherwise unstable sand particles
ADDITIONAL KEYWORDS: Coastal management, dune restoration, dune accretion, emergency response, ecogeomorphology, nebkha, aeolian transport, shadow dune.

Manuscript submitted 15 March 2018, revised and accepted 30 June 2018.

and shoots catch aeolian sand (Maun 2009). As a plant accrues sand at its base and is buried, it will grow vertically over time along with the bedform it is creating. Plants in coastal dune habitats can thus be considered ecosystem engineers that initiate, build, and or stabilize dunes (Woodhouse 1978). Only a handful of plant species worldwide can survive in the foredune (Maun 2009) and establishment rate, survival, and plant height have been noted to affect topography (Hesp 1989). The biophysical feedback loop between vegetation and dune morphology has only recently begun to be explored in the realm of bio- or eco-geomorphology (Stallins 2006; Murray et al. 2008; Zarnetske et al. 2012; Durán and Moore 2013; Fei et al. 2014).

Though they act at different timescales, geology and ecology are inextricably linked in coastal dunes. Geomorphic processes and landforms shape the spatial and temporal distribution of biota, and conversely, biota modify geomorphic processes and landforms (Stallins 2006). Sand transport from the beach to dune is steered by both topography and vegetation, with regards to where accumulation will occur as transport and air flow adjusts to changes in surface conditions (Arens 1996; Hesp et al. 2015). These feedbacks build dune topography and thereby establish a disturbance regime for overwash as a function of topographic relief and complexity (Wolner et al. 2013; Durán and Moore 2013). Theoretical 


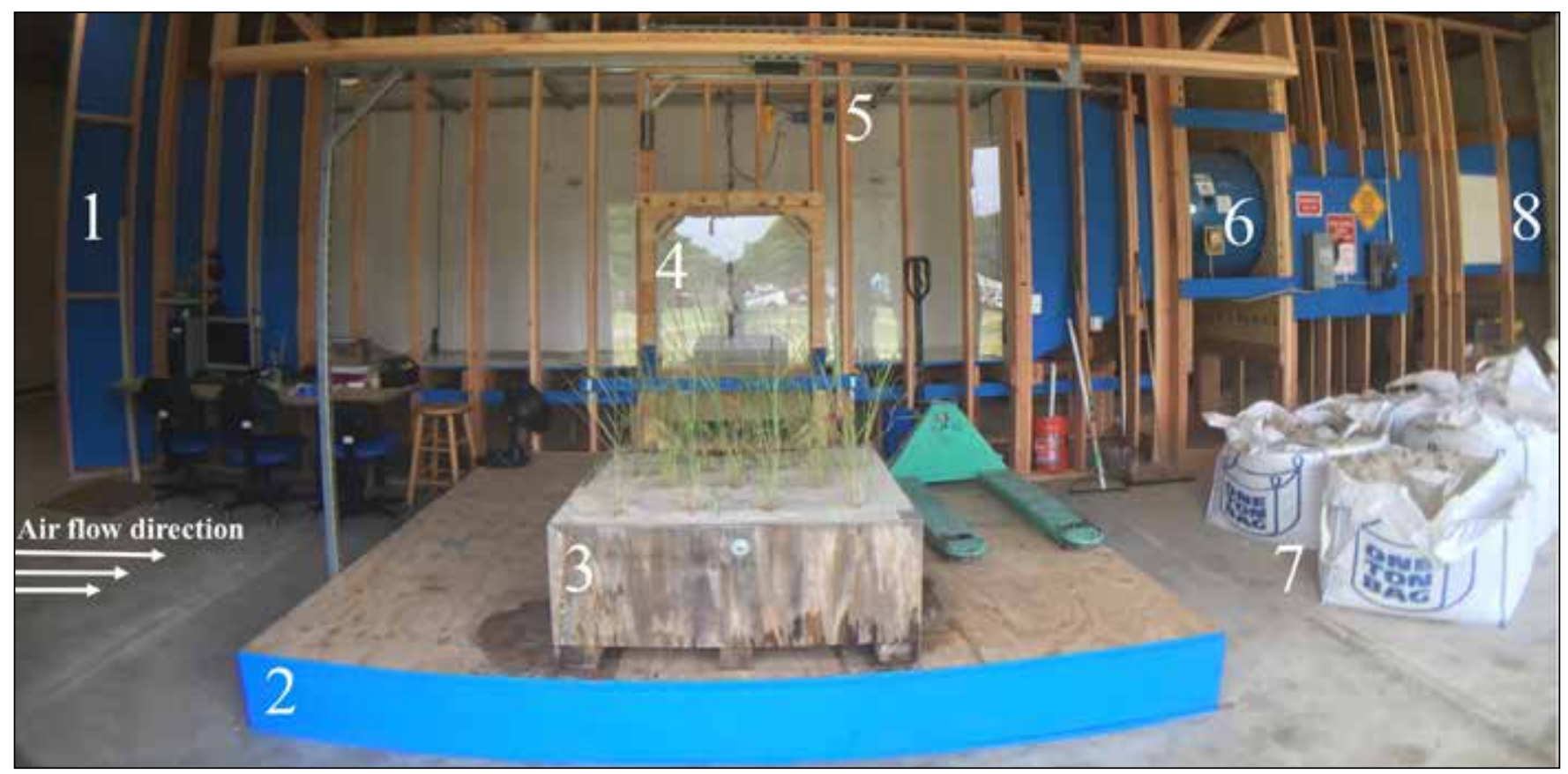

Figure 1. Movable bed wind tunnel built in Waretown, NJ, with USGS and ERDC funding in 2016. The wind tunnel is capable of reaching wind speeds up to $27 \mathrm{mph}(12.1 \mathrm{~m} / \mathrm{s})$ and was designed with ease of use and adaptability in mind for future research applications. The main components are labeled numerically from left to right: (1) air flow inlet; (2) platform to insert boxes into test area; (3) one of the $1 \mathrm{~m} \times 1 \mathrm{~m} \times 0.3 \mathrm{~m}$ boxes in which we established our Ammophila plants; (4) test area where boxes are inserted and sealed into the chamber; (5) 3D sensor and accompanying hardware and tracking; (6) fan; (7) one ton bags of dry sand; and (8) air outflow.

growth of a stable vegetated foredune, from which a berm will grow seaward, can take seven years or more (Zhang et al. 2015). There are multiple stages of dune development (Hesp 2002), and we anecdotally believe that these shapes should vary morphologically as a function of the vegetation steering their formation.

Dune growth can begin with shadow dune and nebkha formation around individual plants or plant communities, ultimately leading to incipient/nascent foredunes prior to the establishment of a mature foredune (Hesp 1989; Hesp 2002). Shadow dunes form on the lee or wake of a discrete roughness element, by reverse flows occurring within the wake region; height of the shadow dune has been linked to the width of the obstruction and is independent of obstruction height (Hesp 1981). Nebkha refers to the accumulation of sand around the plant base due to aeolian deposition which can vary widely in size from $\mathrm{mm}$ to meters (Cooke et al. 1993). Dune nebkha research focuses on established nebkhas as opposed to inception (Gillies et al. 2014; Hesp and Smyth 2017). Nebkha and shadow dunes are linked; shadow dune length and wake zone length increase gradually with nebkha diameter (Hesp and Smyth 2017). Nebkhas and shadow dunes are, therefore, hard to distinguish from one another and in this study, will be referred to as bedforms. Bedforms are features that develop at the interface of fluid and a moveable bed, from the motion of material in flow, and in this study, represent a shadow dune-nebkhacomplex (SDNC).

Only with enough time and deposition would we could expect substantial SDNC formation. Initial accumulation can be thought of as ephemeral, but we believe it may also translate throughout the dune evolution (Hacker et al. 2012; Ping et al. 2014). If we expect a taller and steeper plant to build a taller and steeper dune (Hacker et al. 2012), then the relationship between plant morphology and geomorphology should persist through the evolution of the dune. Furthermore, wind speed and plant density will impact flow and, thus, accretion or erosion within a plant stand (Sarre 1989) with narrower spacing resulting in a steeper and narrower dune (Hesp 1983; Hesp 1989).

We are interested in the potential variability surrounding initial bedform creation and shape around individual plants within stands of different densities at the onset of a management effort. We built a movable-bed wind tunnel to examine the effect of plant density on SDNC formation around American beachgrass (Ammophila breviligulata). We focus on A. breviligulata as opposed to other foredune plants, because it is the most commonly used dune building and stabilizing plant on the U.S. mid-Atlantic coast (Woodhouse 1978). Vegetation density is considered a more important factor in foredune formation than vegetation type (Hesp 1983; Hesp 1989), so we have chosen to focus on planting density rather than plant species. Planting studies and guides, both seminal and new, suggest various planting densities depending on site characteristics, objectives, and sediment supply, falling in the range of 12-40 inches $(30.5-102 \mathrm{~cm})$ planting on center with $12-18$ inches $(30.5-45.7 \mathrm{~cm})$ being most common (Savage and Woodhouse 1968; Jagschitz and Wakefield 1971; Seneca et al. 1976; Dahl and Woodard 1977; Knutson 1977; Woodhouse 1978; O'Connell 2008; Wootton et al. 2016). We therefore tested 12 inch and 18 inch on center planting densities. We hypothesized that planting density will affect the volume of the bedforms created, as well as their shape, and that differences in shape will be related to the width of the base of the plant. Understanding how density affects bedform shape should be considered when making management decisions to build effective dunes. 


\section{METHODS}

Wind tunnel description

We built a movable-bed unilateral suction flow wind tunnel in Waretown, NJ, USA at the Ocean County Vocational Technical School. Its design was modified from a tunnel once at the O.H. Hinsdale Wave Research Lab of Oregon State University (Zarnetske et al. 2012). The chamber length is $6 \mathrm{~m}$ with a $2 \mathrm{~m}$ cross section $(2 \mathrm{~m} \times 1 \mathrm{~m}$ height $\times$ width $)$. An opening exists in the bed $3.6 \mathrm{~m}$ downwind, where a $1.0 \mathrm{~m} \times 1.0 \mathrm{~m}$ box ( $0.3 \mathrm{~m}$ deep $)$, which for our purposes contains sand and plants, can be inserted and sealed into the chamber at bed height. Wind is created by a $20 \mathrm{HP} 460 \mathrm{~V} 60 \mathrm{~Hz} 3$ Phase JM Direct Driven Aerofoil fan with a 43,000 cfm duty. The actual wind speed attained (27 $\mathrm{mph}, 12.1 \mathrm{~m} / \mathrm{s}$ ) matched well with the expected maximum (27.3 mph or $12.2 \mathrm{~m} / \mathrm{s}$ ), based on chamber size and fan output. The fan pulls air into the chamber though a wall of 1.5 " $(3.8 \mathrm{~cm})$ diameter honeycomb arrayed pipes that straighten the air to reduce turbulence towards laminar flow. The air exits the chamber through a louvre. Wind speed can be altered via a variable frequency drive controlling the fan. Wind speed can be monitored via five SPER Scientific ${ }^{\circledR} 840003$ digital turbine anemometers upwind and downwind of our test area and observed to ensure uniform sand transport. These can be moved throughout the chamber, and log both temperature and wind speed with accuracy $\pm 0.6^{\circ} \mathrm{C}$ and $\pm 3 \%$, respectively (Figure 1 and 2). We tested the tunnel free stream wind velocity by altering fan speed and logging the resulting wind speeds occurring over a two-minute period at various heights and locations within the wind tunnel. To do this, we used a Speedtech WM-300 WindMate ${ }^{\circledR}$ (wind speed accuracy $\pm 3 \%$ ) mounted to a vertical pole affixed to the chamber ceiling and floor and or horizontal pressure rod to create horizontal and vertical velocity profiles (Figure 3). Effects of the walls and ceiling are generally minimal and boundary layer thickness and flow is as would be expected following a logarithmic increase from the walls, floor, and ceiling.

Three-dimensional surface topographic data can be collected via an industrial class II laser 3D sensor, specifically, a SICK TriSpector1060 (SICK 2017). The sensor is a standalone vision product that uses laser triangulation and integrated data processing to acquire

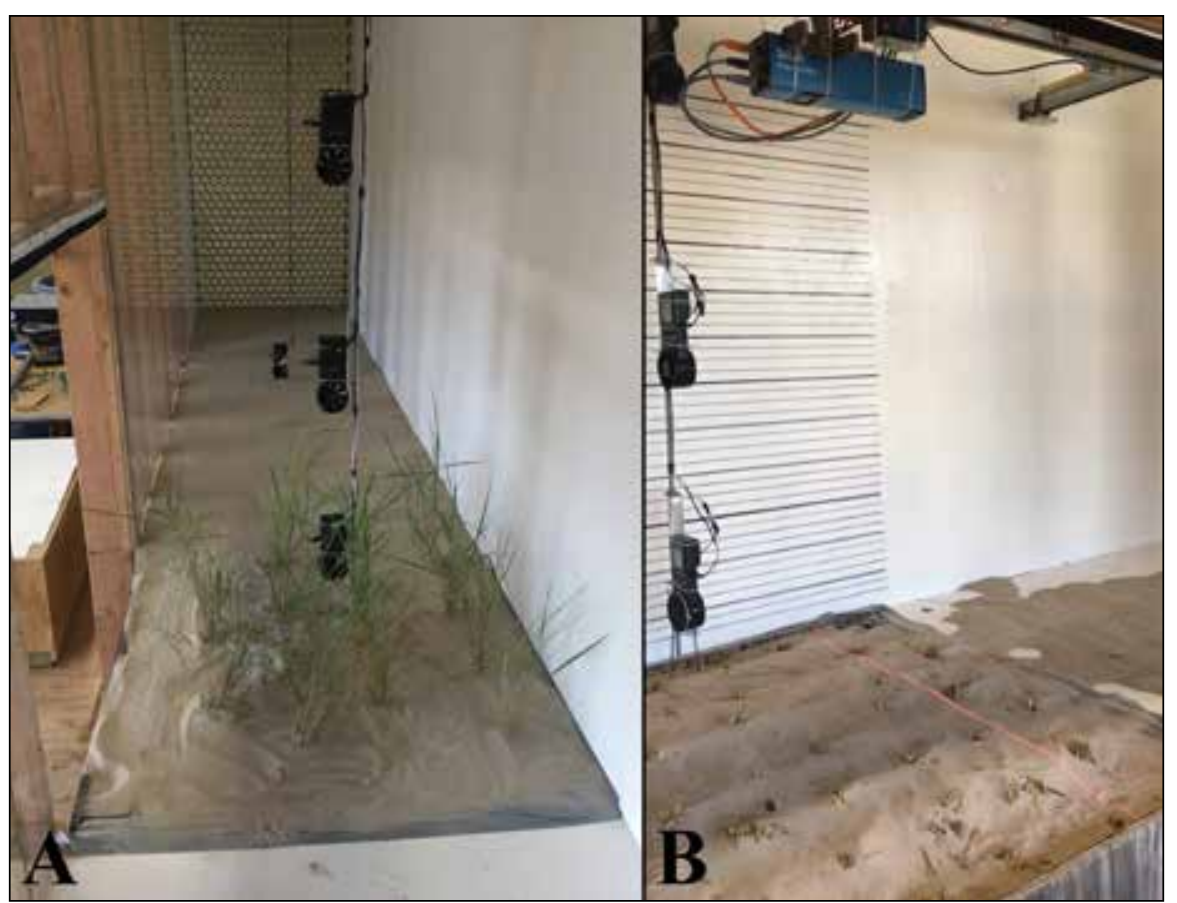

Figure 2. Inside the wind tunnel chamber. (A) Pre-experiment, a $1 \mathrm{~m} \times 1$ $\mathrm{m} \times 0.3 \mathrm{~m}$ box is sealed into the test area level with the $3.6 \mathrm{~m}$-long upwind chamber bed. Prior to trials the bed and box are leveled to a 1-inch (2.54 $\mathrm{cm}$ ) uniform height. Here the upwind bed has been leveled, but the box has not yet been leveled. Turbulence is reduced as the air is pulled through the honeycomb wall into the chamber and towards the plants. The four black sensors are moveable anemometers. The three vertical anemometers provide a wind profile in the test area among the plants, and there is also an anemometer upwind and downwind (cannot be seen in the photo) of the test area. (B) Post-experiment, all above-ground plant material has been cut from surface using shop shears. Only plant parts too close to the surface to cut without disturbing the bedforms remain. The 3D sensor is mounted on a track that has been lowered toward the bed from the ceiling for data acquisition. The 3D sensor is mechanically pulled over the test area to scan the topography with the red laser denoting the area the sensor is currently passing over.

multiple height $(Z)$ profiles along an $\mathrm{X}$ and $\mathrm{Y}$ range that it stitches together in real-time to build a 3D image of the surface. It produces factory calibrated data with true mm values in all dimensions at a height resolution of $80-670 \mu \mathrm{m}$, eliminating the need for post-processing of dense point cloud data (Remondino 2003). The sensor and its track are attached to the tunnel ceiling and can be retracted so they do not affect wind flow to the test area. To collect data, the track must be lowered, via a mechanical winch so that the sensor is 43 " $(109 \mathrm{~cm})$ above the box area to give the maximum allotted scan width (X) of 26 inches $(66 \mathrm{~cm})$ (Figure $2 \mathrm{~B})$. The scanner is mechanically pulled along its track, smoothly and at uniform speed, over the test area. It can collect 2,500 profiles per scan to create the $3 \mathrm{D}$ image; the distance between profiles can be manually set along a 49 -inch $(1.25 \mathrm{~m})$ max scan length (Y) modulated by a wire draw encoder. For our application, the 3D sensor captured height profiles $(Z)$ every $0.42 \mathrm{~mm}$ stitched together to create a $3 \mathrm{D}$ image of the topography of each box. More details about the wind tunnel can be found at thewindtunnel.weebly.com.

\section{EXPERIMENTAL PLANTINGS}

In July 2016, we planted nurserygrown A. breviligulata plugs donated by Pineland's Nursery, Columbus, NJ, into the $1 \mathrm{~m} \times 1 \mathrm{~m} \times 0.3 \mathrm{~m}$ boxes filled with dry sand from Island Beach State Park, NJ (mean grain size 0.300-0.350 mm). The plants survived winter to break dormancy in spring 2017. We spaced plants in a regular non-staggered array at one of two commonly used management densities per box, either 12 inches $(30.5 \mathrm{~cm}$; referred to as low-density) or 18 inches (45.7 $\mathrm{cm}$; referred to as high-density) on center, resulting in 8 or 14 plants per $\mathrm{m}^{2}$ box. Both planting densities are low 


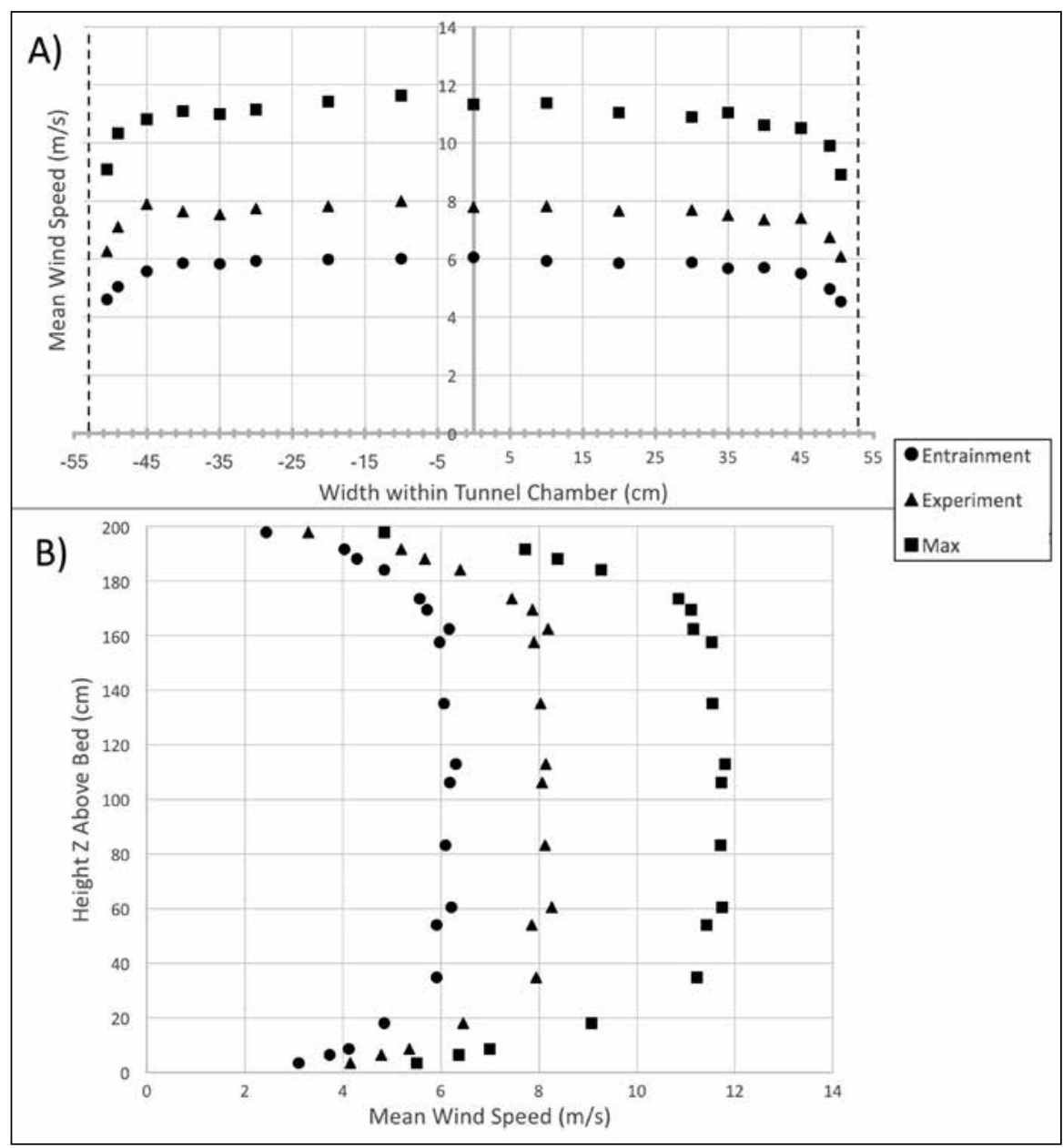

Figure 3. Velocity profiles at three relevant wind speed settings entrainment, max speed, and test speed. Measurements made in the center of the wind tunnel chamber sans plants and with a 1 inch $(2.54 \mathrm{~cm})$ sand bed. Entrainment is relative to our grain size used, mean $0.300-0.350 \mathrm{~mm}$. The height referred to is the height of the center of the anemometer turbine. Figure 3A) The wind tunnel chamber is $106 \mathrm{~cm}$ wide. The effects of the walls are not felt until $\approx 8 \mathrm{~cm}$ from the walls (the dashed vertical lines) at all wind speeds. These measurements were taken $1 \mathrm{~m}$ above the bed, where the effects of the ceiling and floor should be the lowest, at the start of the test area $3.5 \mathrm{~m}$ downwind. Figure 3B) Change in wind speed as a function of height above the bed. Measurements made in the center of the wind tunnel chamber at the center of the testing area, $4.1 \mathrm{~m}$ downwind. The effects of the ceiling boundary layer are felt well above the height of our plants, $58.3 \pm 1.5$ $\mathrm{cm}$, for uniform sediment transport.

compared to the density of Ammophila that has been recorded in naturally occurring stands (Zarnetske et al. 2012; Charbonneau et al. 2016). Because the $3 \mathrm{D}$ sensor is only able to capture a scan width of 26 inches $(66 \mathrm{~cm}), 13$ inches ( 33 $\mathrm{cm}$ ) on each side of the center of the box, there is $\mathrm{a} \approx 7$-inch $(17.8 \mathrm{~cm})$ buffer of space and plants between the tunnel wall and the plants being tested. The effects of the walls are not felt in the test area until $\approx 3$ inches $(8 \mathrm{~cm})$ from the wall such that flow in the scanned area is well buffered and unaffected by the walls (Figure 3A). Similarly, the tunnel is appropriately scaled for using plants such as A. breviligulata as the ways, from base to the top as the plant was bent naturally, the bent height, and from the base to the highest leaf tip by pulling the leaves taught, the straight height. We collected these morphology data with the help of nine volunteer high school students from the Marine Academy of Technology and Environmental Studies (MATES) on 30 August 2017.

\section{EXPERIMENTAL TESTS \& MEASUREMENTS}

We conducted all tests the first two weeks of September 2017. Tests consisted of 30 minutes in the wind tunnel with wind controlled at a constant $18.5 \mathrm{mph}$ $(8.25 \mathrm{~m} / \mathrm{s}) 60 \mathrm{~cm}$ above the surface with entrainment occurring at $12.8 \mathrm{mph}(5.7$ $\mathrm{m} / \mathrm{s})$ and $15.1 \mathrm{mph}(6.75 \mathrm{~m} / \mathrm{s}) 4 \mathrm{~cm}$ above the surface upwind of the test area; we selected this duration and wind speed to be comparable to prior tests by Zarnetske et al. (2012) as well as due to constraints with sand supply and bed erosion. Please see Figure 3 velocity profiles in the test area at various speeds. Tests of this nature at stand level have been and can be done in situ (see Hesp 1989), but ex situ, in a wind tunnel, we have the power to control all factors to hone in on the biotic or abiotic drivers behind bedform development. Prior to an experimental test, we sealed the box being tested into the chamber and then created a continuous and level 1 -inch $(2.54 \mathrm{~cm})$ dry sand bed upwind of the box using a custom fabricated rake; the smooth upwind bed mimicked a flat dry sand backshore, and thereby natural conditions for sand transport (Arens 1996).

As a class II laser the 3D sensor cannot penetrate live tissue, so our tests had to be destructive, i.e. we had to remove the plants to scan the underlying sand topography; post-experiment, we cut all aboveground plant material from the top of the sand surface via shop shears without shifting the sand (Figure 2B). We took three different 3D scans of each test box: a pre-experiment 3D scan of the level box, post-experiment before cutting off the plants, and post-experiment after cutting off the plants. Three scans allowed us to compare the starting and end height of sand around each plant to determine if erosion or wake shielding formed the bedforms around plants, or whether sand accumulated. We transported the harvested plant material to the University of Pennsylvania to determine biomass as the dry weight of the samples after $72 \mathrm{hr}$ at $70^{\circ} \mathrm{C}$. 


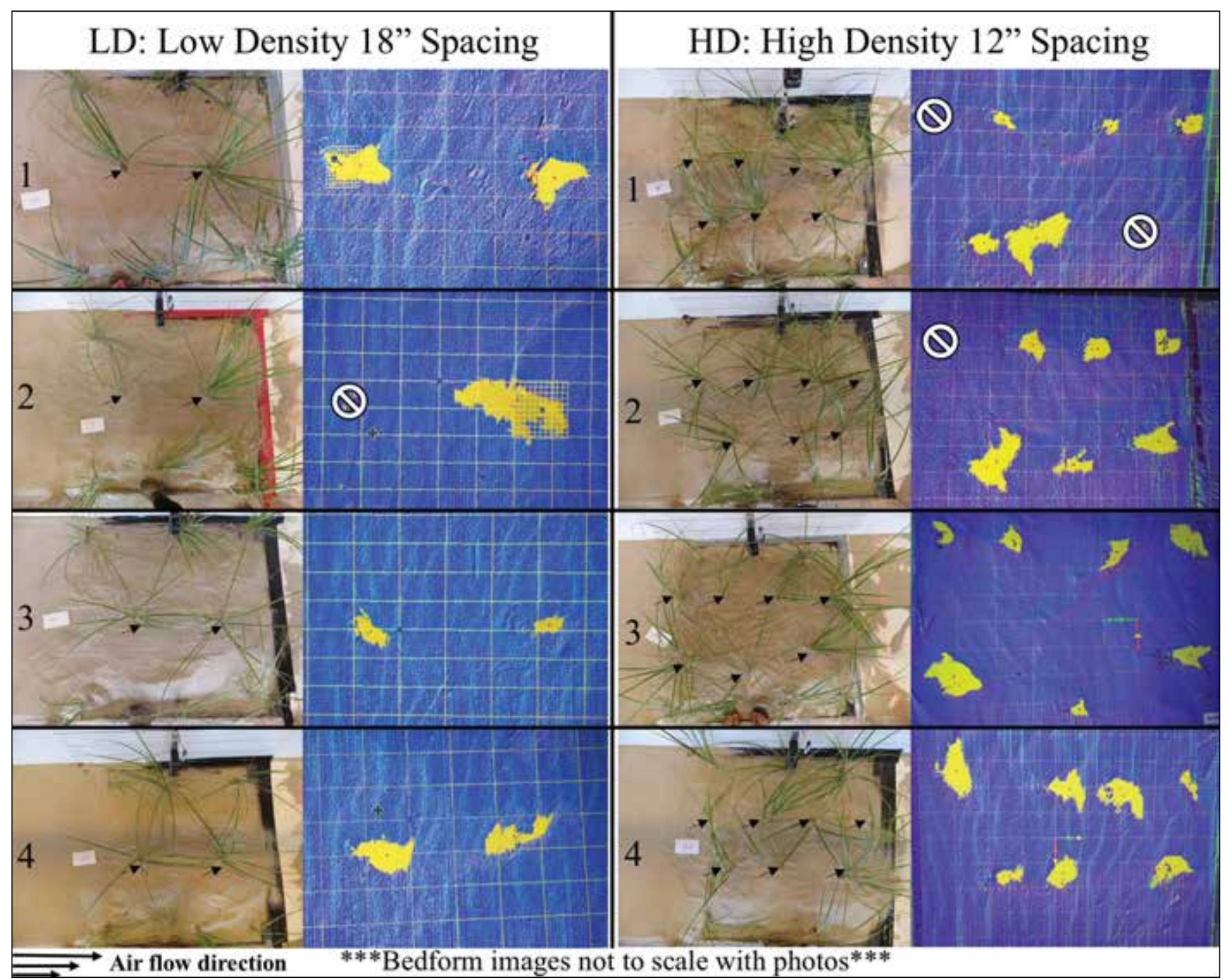

Figure 4. Images of the four planted boxes pre-experiment for the two density treatments and the resulting bedforms formed around the bases of the plants. The black arrows point to each plant base pre-experiment in overhead photos. Note, the plants went dormant and grew back such that the spacing was slightly askew in some boxes. The blobs on the right side of the images represent the bedforms as found by the Blob Tool viewed overhead in SOPAS. The SOPAS images are not to scale among images or with their accompanying overhead plant picture. There were four instances where no bedform formed around a plant base, denoted with a cross-out symbol, $n=7$ bedforms for lowdensity experiments and $n=25$ for high density.

\section{STATISTICAL ANALYSES}

We used SICK's SOPAS Engineering Tool to extract bedform volume and area (the footprint or basal area of the bedforms) as quantitative values from our 3D images. We used JMP Pro 13.0 to perform statistical analyses on these and the plant morphological metrics. All means are reported \pm standard error (S.E.). We included the ordinal variable row in analyses as it is relevant with regard to upwind plants shielding downwind plants. These data were not equal in sample sizes among densities given the number of plants per test and similarly were not independent within boxes. Therefore, we used R, version 3.4.0 (R Core Team 2017) to fit linear mixed-effects models (LMM) using restricted maximum likelihood (REML) with box number treated as a random effect in all tests. Specifically, we tested if bedform volume, basal area, and shape varied as a function of the fixed effects density, biomass, width of stems, and row where row is treated as an ordinal variable. We used a stepwise analysis for automated model selection with subsets of the supplied "global" model and report the most supported based on $\triangle \mathrm{AIC}$ and AIC values with a criterion of models having a $\triangle \mathrm{AIC}<4$ (Goodenough et al. 2012). We analyzed the significance of our model effects using a likelihood ratio test (LRT).

The 3D sensor creates .png files that, when read in SOPAS, can be analyzed by deploying tools to find, inspect, and measure features (SICK 2017). We used the Fix Plane and Blob tools to locate bedforms in our post-experiment scans. The Blob tool locates point clusters within a defined $3 \mathrm{D}$ area and height range; it calculates the basal area of clusters, which in this case, are the bedforms formed by a plant, and the volume from the base of each bedform; bedform base is set manually per bedform with the Fix Plane tool as a function of pixel clumping. The Blob tool can be applied across the entire field of view or to smaller sections; we applied multiple Blob tools per box, one where each plant had been located as well as determined the bedform peak. From the scans, we manually measured the $\mathrm{Y}$ 


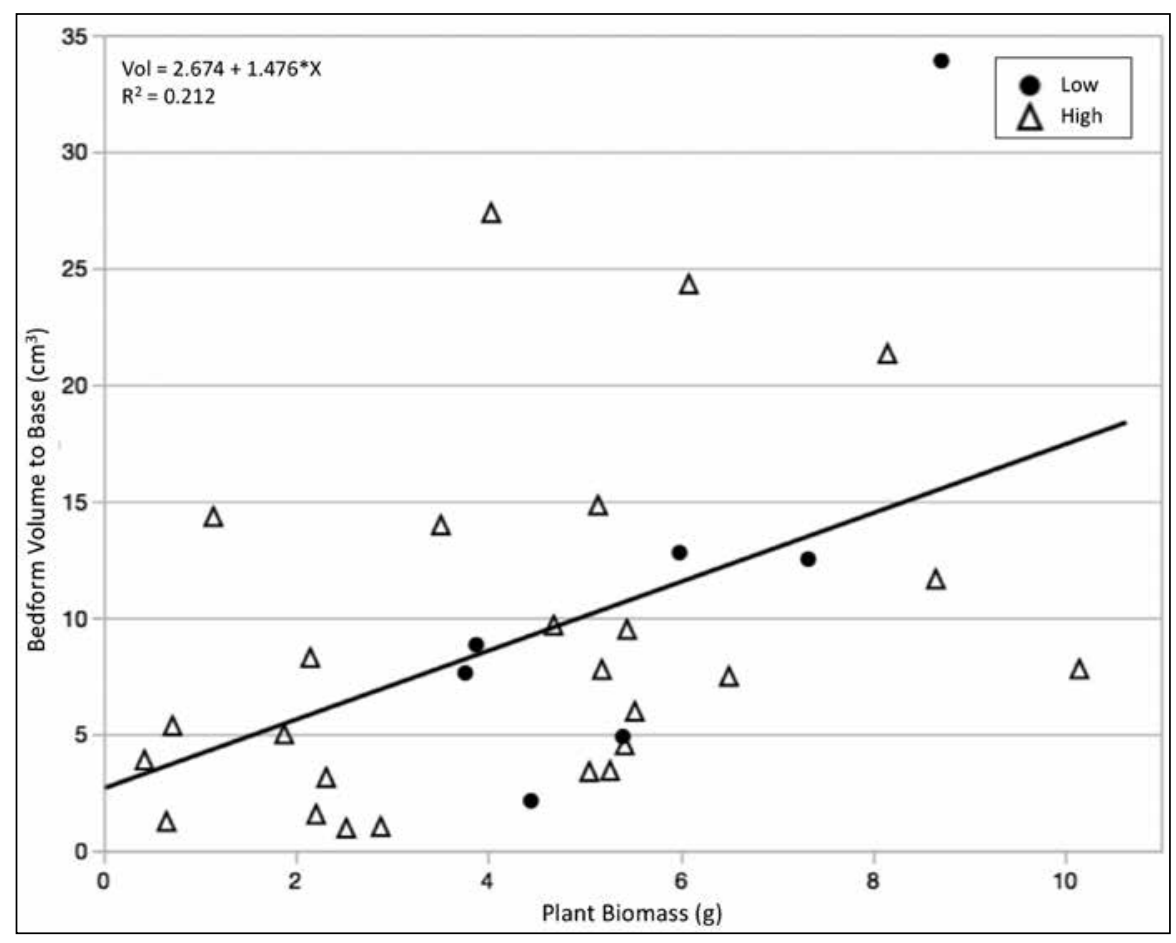

Figure 5. Plant biomass had a significant effect on bedform volume $\left(F_{1,30}\right.$ $=8.07 ; \mathbf{R}^{2}=0.21 ; P=0.008$ ) with larger plants producing larger bedforms regardless of plant position in the box (row), density, or stem width. Planting density, high (12 inches) or low (18 inches) did not have an effect.

length and $\mathrm{X}$ width of each bedform as the distance between the maximum $X$ and Y extents and divided length by width as a metric of shape. Despite spike signatures from the laser not being able to penetrate plant tissue, we manually discerned the starting height of the sand at the base of each plant in the pre-experiment scan, using the Fixed Plane tool. By comparing base heights to the post-experiment bedform peak, we could determine if erosion or accretion created the bedforms and compare bedform height and net height change as a function of density and row with Pearson's Chi Square Tests. Lastly, we measured upwind bedform angle using a line tool drawn from the base of the bedform as defined by the blob tool, to the defined peak. We compare bedform angle as a function of morphology and density in a LMM whereby we report the results of the LMM fixed effects test; we report the same statistic tests to compare plant morphology among density treatments.

\section{RESULTS}

Our A. breviligulata plants $(\mathrm{N}=$ 36) had the following morphology ( $x$ \pm S.E.): number of leaves per plug 14.9 \pm 1.3 ; stems per plug $4.2 \pm 0.4$; width of the stems $3.7 \pm 2.5 \mathrm{~cm}$; plant height 75.3 $\pm 1.2 \mathrm{~cm}$ when pulled straight; height at natural bent $58.3 \pm 1.5 \mathrm{~cm}$. None of the above morphology measurements varied statistically as a function of trial density, nor did biomass $4.5 \pm 0.4 \mathrm{~g}$ (Fixed Effects Test; $P=0.51)$.

Bedforms formed in all experimental tests (Figure 4). The control tests, just dry sand with no plants, resulted in the creation of small ripples on previously flat sand, but no detectable point clusters to define blobs, i.e. bedforms beyond ripples. Similarly, these ripples were of uniform size and shape along the length and width of our scanned test area. We expected one bedform per plant, but not every plant resulted in the formation of a bedform. Bedforms did not form around four plant bases in total, most of which we observed did not form around the first upwind plant, resulting in $\mathrm{N}=$ $32, \mathrm{n}_{\text {Low }}=7$ and $\mathrm{n}_{\mathrm{High}}=25$. See Figure 4 to view the bedforms and the specific boxes/ instances where bedforms did not form.

Plants can create bedforms either as a function of erosive or accretionary sediment flux. Of the seven plants forming bedforms in the low-density experiments, we observed no net change in start and end height for one bedform and the other six were the result of accretion. For the high-density boxes, it was not possible to discern the starting height around the base of the plants for one full box and its seven bedforms, as well as some other individual plants, bringing our sample size examining net height change to $\mathrm{n}=$ 18 as we observed accretion, erosion, or no net change 9,8 , and one time, respectively. Comparing among erosive vs. accreted bedforms, we see that low-density treatment bedforms formed more than expected from accretion and less than expected from erosion and vice versa for high-density treatments $\left(X^{2}{ }_{1}=4.33 ; P=\right.$ 0.04). Comparing mean height change between densities confirms these results as there is a trend for high-density boxes incurring lower net change $\left(\bar{x}_{\text {Low }}=7.3\right.$ $\pm 2.8 \mathrm{~mm}, \overline{\mathrm{x}}_{\text {High }}=-0.7 \pm 1.2 \mathrm{~mm} ; \mathrm{F}_{1,5}=4.7$; $P=0.06)$. Examining only the height change of accreted bedforms we see there is no difference as a function of density $\left(\overline{\mathrm{x}}_{\text {Low }}=7.3 \pm 2.8 \mathrm{~mm}, \overline{\mathrm{x}}_{\text {High }}=3.1 \pm 0.5 \mathrm{~mm}\right.$; $\mathrm{F}_{1,4}=0.9 ; P=0.39$ ). Our mixed models support this and lends further insight, as neither the height change looking at erosion and accretion, or net gain looking only at accretion, varied with row, biomass, width of stems, or density (LRT; $P>$ 0.05). The amount of biomass upwind of each plant did not affect net height change (LRT; $P>0.05$ ) and the upwind angle of the bedforms did not vary by density or any metrics of plant morphology (Fixed Effects Test: $\mathrm{P}>0.05)$ such that the mean angle is $9.36 \pm 0.67^{\circ}$.

Biomass is the only predictor of bedform volume. The best model comparing models fitted by REML included biomass along with density and row with no significant interactions between effects. Within this, biomass was the only predictor that affected bedform volume (LRT; biomass $\chi^{2}=4.17, \mathrm{P}<0.05$; density $\chi^{2}=$ $0.04, \mathrm{P}>0.84$; row $\chi^{2}=2.20, \mathrm{P}>0.53$ ). Plants with greater biomass produced bedforms of greater volume $\left(\mathrm{F}_{1,30}=8.07\right.$; $\mathrm{R}^{2}=0.21 ; P=0.008$; Figure 5). Model selection examining parameter effects on bedform area only produced one model, which included biomass, density, row, and stems width as effects. However, none of these predictors had a significant effect on bedform area (LRT; biomass $\chi^{2}=0.42, \mathrm{P}$ $<0.50$; density $\chi^{2}=0.94, \mathrm{P}>0.93$; row $\chi^{2}=1.5, \mathrm{P}>0.68$; stem width $\chi^{2}=1.98$, $P>0.15)$.

Though the bedforms did not vary in volume or area as a function of density, they varied in their relative shape. The low-density treatment produced longer bedforms while bedforms in the highdensity treatment were more uniform 
in shape $\left(\overline{\mathrm{x}}_{\text {Low }}=1.67 \pm 0.20, \overline{\mathrm{x}}_{\text {High }}=1.11\right.$ $\pm 0.06 ; \mathrm{F}_{1,15}=17.34 ; P=0.0008$; Figure 6) Our mixed model tests confirmed this result as model selection for bedform shape only selected one model, and that model included only density as a fixed effect within the model and only density having a significant effect as a predictor of bedform shape (LRT; density $\chi^{2}=10.15, \mathrm{P}$ $<0.001$; all others: biomass $\chi^{2}=1.55, \mathrm{P}<$ 0.21 ; row $\chi^{2}=3.18, \mathrm{P}>0.37$; stem width $\left.\chi^{2}=0.07, \mathrm{P}>0.79\right)$.

\section{DISCUSSION}

We have shown that bedform volume and area varied with plant biomass, but not density. We expected plant density to factor into bedform morphology as plant density is a dominant factor controlling surface roughness and thus sand transport at the stand level (Bressolier and Thomas 1977; Hesp 1983; Hesp 1989); shear velocity varies with changes in lateral cover (frontal area of canopy elements per unit ground areas), which increases with greater vegetation (Wolfe and Nickling 1996) and is used as a predictor of stand level deposition (Raupach 1992). However, changes in plant density have also been found not to translate to differences in friction and thereby flow velocity and deposition at the stand level with non-uniform objects, such as live plants (Järvelä 2002). Similarly, lower densities of vegetation have been found to enhance transport compared to higher (Burri et al. 2011). Our densities may not vary in lateral cover enough to produce the above effects despite there being more biomass in the high-density treatment, so perhaps it is appropriate not to expect to see an effect of density on deposition volume or area. Regardless, these results would still be comparable to the effect of density as felt by the first few rows of plants in situ after a planting at the same wind speed. Lastly, deposition in the lee of the vegetation can depend most strongly on object porosity, height and downwind position (Leenders et al. 2011), and the permeability of the object with tail lengths decreasing with reducing porosity (Gillies et al. 2017). Biomass is likely linked to porosity as a function of the width of stems and height, with larger plants being taller and wider at their bases - the physical properties of the individual plant or roughness component seems to be more important than their array, at least at the two densities tested. How bedform components relate

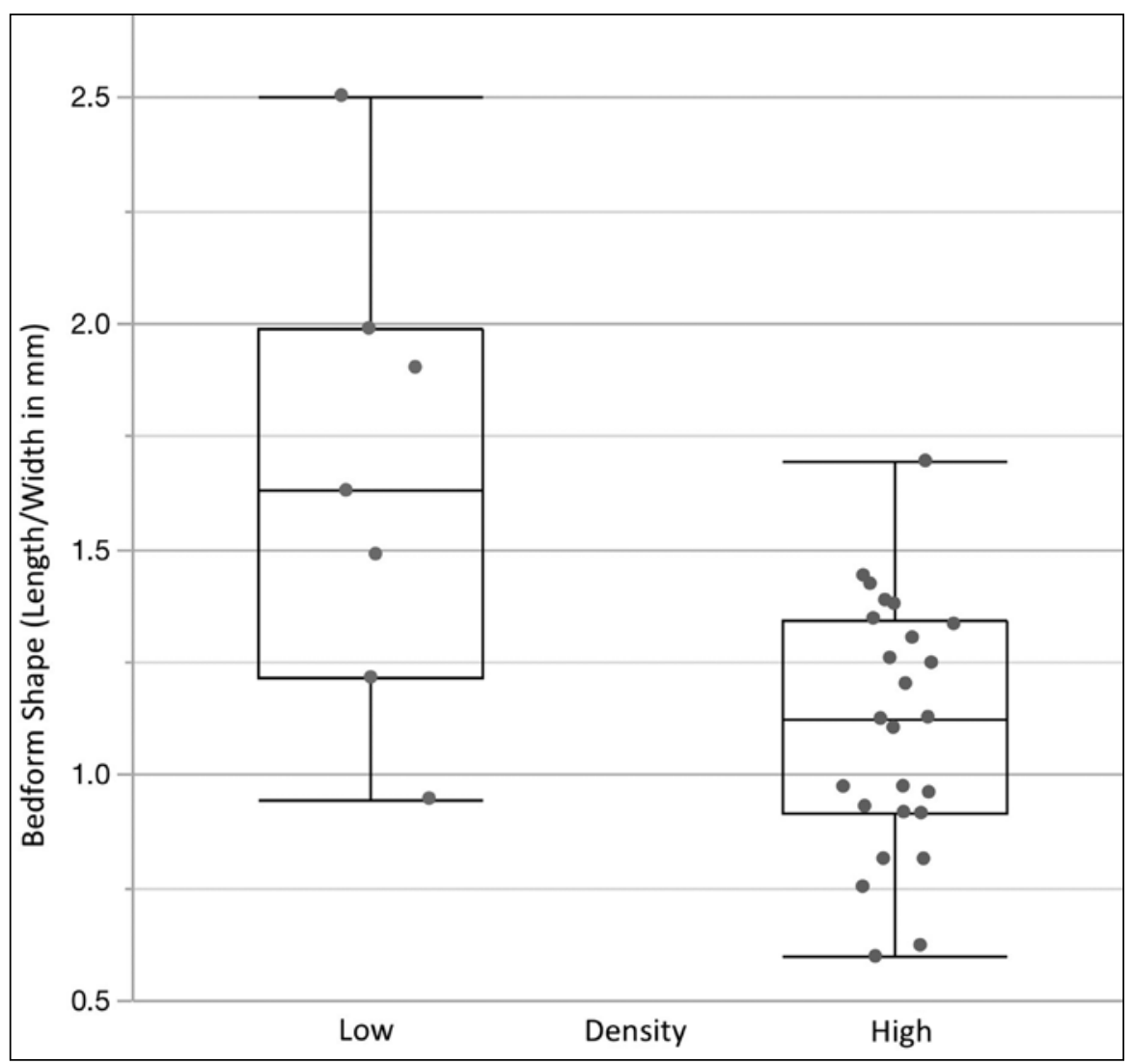

Figure 6. If the bedforms were uniformly shaped, then the ratio of length to width would equal 1.0. However, we see that bedform shape was greater than 1.0 and varied by density, with the low-density treatment producing bedforms with longer $Y$ extents, (i.e. tails) compared to the high-density treatment which were more uniform in shape $\left(\bar{x}_{\text {Low }}=1.67 \pm 0.52, \bar{x}_{\text {High }}=1.11 \pm 0.28\right.$; $\left.F_{1,15}=17.34 ; P=0.0008\right)$. Shape was not affected by plant position in the box (row), or stem width or biomass $(P>0.05)$.

to specific morphological parameters beyond plant width is out of the scope of this paper and will be addressed in later research.

We were surprised to find that plant base width, was not a predictor of bedform area or volume. Other studies have observed that wider bases result in greater bedform area e.g. Hesp (1981) and Hesp and Smyth (2017). Increased lateral cover, which will increase with wider plants offering more upwind surface area, has been linked to increased deposition at the stand level (Raupach 1992). Similarly, Leenders et al. (2011) found that higher porosity plants (offering more surface area or wider bases) in situ, reduce wind speed more than lower porosity plants resulting in lower deposition behind plants offering less of a barrier to wind velocity. Therefore, we might expect to see width of stems affecting both bedform volume and area. Perhaps our 30-minute trial duration was too short and for future experiments should be increased to 45-minutes+ and or our sample size too small.
We chose this experimental duration to be comparable to Zarnetske et al. (2012), as well as due to bed erosion relative to sand supply. Similarly, the heterogeneity of our observed bedform volumes is great compared to our limited range of plant widths determined by planting nursery grown plugs that were fairly uniform in shape. It is possible that plant size did not vary enough in our experiment to discern a relationship between plant width and bedform volume. Managers recommend planting two culms of beach grass per hole (Skaradek et al. 2003) in planting efforts and these results would suggest that planting more culms per hole may be beneficial as a larger porous obstruction, width and biomass, may produce greater accumulation.

We find it interesting that planting row did not have an effect on bedform size or shape, yet three of the four plants that did not form bedforms were in the first row of plants. We expected increasing deposition past the leading upwind row of plants as a result of varying shear velocity (Wolfe 
and Nickling 1996), increased drag, and downwind deceleration (Hesp 1983). The spatial distribution of the main body of vegetation creates a complex velocity field and directly influences the shape of the vertical velocity profile (Boothroyd et al. 2016), and thereby deposition. Wind tunnel tests are often made at the level of the plant stand and with regards to mass flux (Hesp 1983; Arens 1996; Järvelä 2002; Burri et al. 2011), below a critical vegetation density, roughness elements (i.e. obstructions), have been found to act independently in the flow (Hesp 1983). Previous findings may not translate when comparing the sand flux relative to a single plant, we may be using too low of a density, wind speed, planting length, and or sample size to discern an effect of row and/or a staggered planting array is needed.

Though we did not find that density affected bedform size, we did find that it affected shape. Specifically, the lowdensity experiments produced bedforms with longer $Y$ extents, (i.e. tails) compared to the high-density treatments which were more uniform in $\mathrm{X}$ vs. $\mathrm{Y}$ extents. This supports the recent work of Gillies et al. (2017) which demonstrated that tail length decreased with reducing porosity and that cube forms collected a greater proportion of sand flux than round cylinders, regardless of porosity. We believe that this result is a function of wake zone and plant leaf interactions diverting air flow, and thus deposition, away from idealized flow in the high-density treatments. Plants will undergo streamlining and compression under shear stress; in lower density instances, the plants are less likely to affect the shearing profiles created around neighbors thereby producing more streamlined bedforms reflecting the idealized flow around an object. An analysis of the splay of the plants would confirm this, but at higher densities, the plants begin to encroach on one another and leaves and stems may be blown into one another, causing eddies and turbulent kinetic energy below the canopy (Raupach et al. 1996), which could push the plants into states other than streamlined downwind. These results would suggest that planting at higher densities reduces the effect of the individual plant such that bedform shape is likely a function of neighbor interactions as opposed to specific morphological plant traits.

We observed both sand erosion and sand accretion at the plant bases, the latter of which can be considered the first stage of shadow dune and nebkha formation. Only ripples formed in the absence of plants. In the case of accretion, the height of the bedform was not influenced by plant density, stem width, row, or biomass. Some other plant morphological factor, such as leaf number (Järvelä 2002), may have affected air drag and flow and thus bed friction. We were surprised to find that biomass and width did not affect bedform height - this could be a function of too short a test duration. Localized vegetation scour (erosion around the plant, especially at its upwind face) has been observed to increase as porosity decreases in emergent and submerged vegetation (Yagci et al. 2016) such that we would have expected less accretion with greater biomass and stem width. We believe the erosion or scour we observed in the high-density boxes is a function of overlapping wake zones in the sheltered lee side of plants and interaction among leaves when plants are spaced closer together. These factors likely increased turbulent kinetic energy and created turbulent wind flow at the micro-scale to trigger erosion in the form of scouring (Leenders et al. 2011; Burri et al. 2011). However, we observed no erosion in the low-density boxes and we believe that our observation of approximately 50/50 erosion vs. accretion is likely high since it was not possible to discern the base height around our plants pre-experiments for $1 / 3$ of the boxes. Therefore, for future experiments, a different metric to discern initial base height, should be employed or the previous method improved.

Bedform height was relatively low, but likely representative of the wind speed, test duration, stem widths, and/or plant height, the latter of which we did not explore. Bedform height has been linked to bedform width as a function of grain size with larger (i.e. wider) obstructions producing greater accumulation and the maximum height depending on grain size (Hesp and Smyth 2017). The height of a shadow dune has been linked to obstruction width independent of obstruction height (Hesp 1981). However, the height to which a shadow dune can be built is linked to plant width and grain size due to the angle of repose (the steepest angle at which the sand is stable) of the grains - once the peak of the bedform reaches the angle of repose any new sand trans- ported onto the shadow dune rolls down the slope and can be transported away by the higher velocity flows at the edge of the bedform wake. Thus, the greater the plant width, the greater the potential height to which the dune, or a bedform, can be built before the limiting angle is reached (Hesp 1981). Though this relationship between height and width was defined for established shadow dunes, we would expect the relationships to hold true at the onset of accumulation if the limiting angle has been reached. Based on the upwind angle of our bedforms, we do not believe that limiting angle was reached during our experiments such that our results are more a function of plant morphology than the physical limits of the grain size used. The height of bedforms we observed may not vary because our plugs were fairly uniform in plant width, but greater height may have been reached with more time to attain the limiting angle. Regardless, accumulation at the individual plant level and at the onset of a planting vegetation can be small, but will build up theoretically over time as more plants accumulate (Hesp 1989); Mendelssohn et al. (1991) found that without fencing, planted vegetation (Panicum amarum, Uniola paniculata, and Paspakum vaginatum) only accumulated $0.6 \mathrm{~m}^{3}$ per meter of beach over a 14 -month period. We suggest planting a greater number of culms per hole to increase plant width and thereby bedform height.

In the absence of plants, we found that there were no discernable bedforms created. Our control boxes, with just sand, resulted only in the formation of ripples with all other abiotic factors being equal. This emphasizes the importance of an obstruction to begin the process of bedform formation initially. These ripples were of uniform shape and size vertically and horizontally, and regularly spaced in our test area. This demonstrates that boundary layer effects from the walls of the tunnel were not felt in the test area, which is buffered by $\approx 7$ inches $(17.8 \mathrm{~cm})$ of space (for control boxes) and of space and plants (for experimental boxes). Similarly, velocity profiles display the expected changes in wind velocity as a function of distance from both the ceiling and floor of the tunnel support the proper aerodynamics of flow within the tunnel.

A study like this can be conducted in situ, but there are benefits to approaching the effect of planting density ex situ in a wind tunnel. Variability in dune 
morphology among sites has been found to depend on the alongshore correspondence of sediment supply and transport potential, which varies with beach state (Houser and Matthew 2011). However, the role of biotic conditions as it relates to ecogeomorphology have only recently begun to be explored (Renken 2015; Goldstein et al. 2017) beyond the role of vegetation spacing evenness and cover heterogeneity (Hesp 1989). By controlling wind speed and direction and sediment supply, we factor out abiotic wind forcing (speed, direction, and sand transport), and focus on the biotic effect of plants, specifically density. It is important to note that our Ammophila did not vary morphologically as a function of density, and we controlled for a potential effect of morphological differences among trials by including box as a random effect in our mixed models. Introducing more morphological variability, as would be expected in nature, is a logical next step for future directions. Variability as a function of planting array - regular or staggered - would also be interesting. One study found no merit in planting staggered vs. non-staggered (Savage and Woodhouse 1968). However, we feel our observations might differ by staggering plants as this would consequently change the flow velocity field to decrease flow within the canopy and thus promote more deposition by reducing the formation of channels between rows of plants.

A study like this can also be conducted with artificial plants, but there are benefits to approaching the effect of planting density with live plants. More is known about the effect of wind on rigid, submerged, and emergent vegetation than on flexible roughness elements or live plant material (Järvelä 2002; Burri et al. 2011). However, solid vs. porous vegetated obstructions do not respond equivalently with regards to flow field and sediment flux responses (Gillies et al. 2014), and therefore, we would not expect plants to either. Similarly, artificial cylinder-like obstructions have been found to produce more volumetric deposition than actual porous plants, so tests on artificial obstructions may not translate to conditions observed in nature (Yagci et al. 2016). Being flexible, plants will undergo streamlining and compression and thus yield more variable heterogeneous velocity field results compared to solid objects. (Yagci et al. 2016; Boothroyd et al. 2016). As the field of eco- and biogeomorphology grows, we believe earlier studies such as this have the potential to provide foundations for future studies done both in situ and ex situ (Stallins 2006).

\section{CONCLUSIONS}

It is important to understand how biotic and abiotic forcings feeds back on resultant bedform morphology; this is especially true where biotic components function as ecosystem engineers in systems with high ecosystem services, such as riparian areas and terrestrial coastal habitats like dunes and marshes.

We hope this research can aid in guiding efforts to rebuild self-sustained dune systems. We observed both sand erosion and sand accretion to form bedforms, the latter of which can be considered the first stage of shadow dune and nebkha formation. The occurrence of erosive forms might be attributable to an inaccurate measurement of pre-experiment base height or to density with tighter spacing causing greater turbulent kinetic energy from interacting neighbor plants. This research suggests that planting more culms of A. breviligualta per planting hole may be beneficial for accumulating more sand around plant bases to build bedforms and thus increase the size of the resulting barrier that would buffer upland areas in the event of a storm. We suggest this because bedform volume did not vary as a function of planting density, but did vary with biomass. Though we did not find that planting density affects bedform size (volume, area, or height), we did find that it affected shape. Specifically, the low-density experiments produced bedforms with longer Y extents, (i.e. tails) compared to the high-density treatments which were more uniform in X vs. Y extents. Planting at a higher density as a coastal dune management strategy requires more investment in plants and thus money, but planting lower densities of more or higher quality (i.e. larger) plants may be equivalent or even offset any additional cost in the form of increased accumulation over a shorter period and thus shorter dune building times.

\section{ACKNOWLEDGMENTS}

This work was funded by USGS and USACE ERDC via a joint coordination with ASBPA. Research for this project was conducted with government support under contract FA9550-11-C-0028 and awarded by the Department of Defense, Air Force Office of Scientific Research, National Defense Science and Engineering Graduate (NDSEG) Fellowship, 32 CFR 168a. We graciously thank John
Wnek, Edward Crawford, John Biscardi and Ocean County, specifically Ocean County Vocational Technical School, MATES, NJFWS, NJDEP, and Island Beach State Park for their continued support. We thank all of our volunteers, especially the nine MATES high school students who measured our plant morphologies: Quinn Figueroa, Elizabeth Piatkowski, Leah Evangeline, Claudia Schreier, Lea Burton, Emily Rossini, Andrew Beck, Matthew Curie, and Frank D'Agostino; thank you to those of you that helped with the tests as well! We thank Phoebe Zarnetske, Tim Maddox, and Don Barber for their guidance. We thank Handyman Pros, NJ, Anthony $\mathrm{Reo}^{2}$ for building our wind tunnel and troubleshooting and all of our additional local partners: New Jersey FWS, New Jersey DEP, AJ's Jeeps, One Ton Bag LLC, Motion Industries, Air Systems Engineering Inc. (owner Eric Wilts), SICK (Engineer Anna Grimley), Moxley Electronics (owner Dan Kerchner), Pineland's Nursery, Save Barnegate Bay, and EMCO Industrial Plastics Inc., The American Littoral Society, Coastal Transplants, and Pineland's Nursery.

\section{REFERENCES}

Arens, S.M., 1996. "Patterns of sand transport on vegetated foredunes." Geomorphology 17(4): 339-350.

Barone, D.A., K.K. McKenna, and S.C. Farrell, 2014. "Hurricane Sandy: Beach-dune performance at New Jersey beach profile network sites." Shore \& Beach 82(4): 13-23.

Boothroyd, R.I., R.J. Hardy, J. Warburton, and T.I. Marjoribanks, 2016. "The importance of accurately representing submerged vegetation morphology in the numerical prediction of complex river flow." Earth Surface Processes \& Landforms 41: 567-576.

Bressolier, C.F., and Y. Thomas, 1977. "Studies on wind and plant interactions on French Atlantic coastal dunes." J. Sediment Petrology 47: 331-338.

Bridges, T.S., K.A. Burks-Copes, ME. Bates, Z.A. Collier, J.C. Fischenich, C.D. Piercy, E.J. Russo, D.J. Shafer, B.C. Suedel, J.Z. Gailani, J.D. Rosati, T.V. Wamsley, P.W. Wagner, L.D. Leuck, and E.A. Vuxton, 2015. "Use of Natural and Nature-Based Features (NNBF) for coastal resilience." ERDC SR-15-1. U.S. Army Corps of Engineers, Washington, DC.

Burri, K., C. Gromke, M. Lehning, and F. Graf, 2011. "Aeolian sediment transport over vegetation canopies: a wind tunnel study with live plants." Aeolian Res. 3(2): 1-9.

Charbonneau, B.R., 2015. "A Review of Dunes in Today's Society." Coastal Management 43(5): 465-470.

Charbonneau, B.R., J.P. Wnek, J.A. Langley, G. Lee, and R.A. Balsamo, 2016. "Above vs. below ground plant biomass along a barrier island: Implications for dune stabilization." J. Environ. Man. 182(C): 126-133. 
Charbonneau, B.R., L.S. Wootton, J.P. Wnek, J.A. Langley, and M.A. Posner, 2017. "A species effect on storm erosion: Invasive sedge stabilized dunes more than native grass during Hurricane Sandy." J. Applied Ecology 54(5): 1385-1394

Cohen-Shacham, E., G. Walters, C. Janzen, and S. Maginnis (eds.), 2016. Nature-based Solutions to address global societal challenges. Gland, Switzerland: IUCN. xiii +.

Cooke, R., A. Warren, and A. Goudie, 1993. Desert Geomorphology. London: UCL Press.

Dahl, B.E., and D.W. Woodard, 1977. "Construction of Texas coastal foredunes with sea oats (Uniola paniculata) and bitter panicum (Panicum amarum)." International J. Biometeorology 21(3): 267-275.

Durán Vinent O. and L.J. Moore, 2013. "Vegetation controls on the maximum size of coastal dunes." PNAS 110(43): 17217-17222.

Elko, N., K. Brodie, H. Stockdon, K. Nordstrom, C. Houser, K. McKenna, L.J. Moore, J. Rosati, P. Ruggiero, R. Thuman, and I. Walker, 2016. "Dune management challenges on developed coasts." Shore \& Beach 84(1): 15-28.

Feagin, R.A., J. Figlus, J.C. Zinnert, J. Sigren, M.L. Martínez, R. Silva, W.K. Smith, D. Cox, D.R. Young, and G. Carter, 2015. "Going with the flow or against the grain? The promise of vegetation for protecting beaches, dunes, and barrier islands from erosion." Frontiers in Ecology and the Environment 13: 203-210.

Feagin, R.A., N. Mukherjee, K. Shanker, A.H. Baird, J. Cinner, A.M. Kerr, N. Koedam, A. Sridhar, R. Arthur, L.P. Jayatissa, D. Lo Seen, M. Menon, S. Rodriguez, M. Shamsuddoha, and F. Dahouh-Guebas, 2010. "Shelter from the storm? Use and misuse of coastal vegetation bioshields for managing natural disasters." Conservation Letters 3(1): 1-11.

Fei, S., J. Phillips, and M. Shouse, 2014. "Biogeomorphic impacts of invasive species.” Annual Review of Ecology, Evolution, and Systematics 45: 69-87.

Freestone, A. L. and K.F. Nordstrom, 2001. "Early development of vegetation in restored dune plant microhabitats on a nourished beach at Ocean City, New Jersey." J. Coastal Conservation 7(2): 105-116

Gillies, J. A. W.G. Nickling, G. Nikolich, and V. Etyemezian, 2017. "A wind tunnel study of the aerodynamic and sand trapping properties of porous mesh 3-dimensional roughness elements." Aeolian Research 25, 23-35.

Gillies, J.A., J.M. Nield, and W.G. Nickling, 2014. "Wind speed and sediment transport recovery in the lee of a vegetated and denuded nebkha within a nebkha dune field." Aeolian Research 12(C): 135-141.

Goldstein, E.B., L.J. Moore, and O.D. Vinent, 2017. "Lateral vegetation growth rates exert control on coastal foredune "hummockiness" and coalescing time." Earth Surface Dynamics 5(3): 417-427.

Goodenough, A.E., A.G. Hart and R. Stafford, 2012. "Regression with Empirical Variable Selection: Description of a New Method and Application to Ecological Datasets." PLoS ONE 7(3): e34338-10

Hacker, S.D., P. Zarnetske, E. Seabloom, and P. Ruggiero, 2012. "Subtle differences in two non-native congeneric beach grasses significantly affect their colonization, spread, and impact." Oikos 121: 138-148.
Harman, B.P., S. Heyenga, B.M. Taylor, and C.S. Fletcher, 2013. "Global lessons for adapting coastal communities to protect against storm surge inundation." J. Coastal Res. 31: 790-801.

Hesp, P.A., 1981. "The formation of shadow dunes." Journal of Sedimentary Petrology 51(1): 01010112.

Hesp, P.A. 1983. "Morphodynamics of incipient foredunes in New South Wales, Australia." Developments in Sedimentology 38: 325-342.

Hesp, P.A., 1989. "A review of biological and geomorphological processes involved in the initiation and development of incipient foredunes." Proc. of the Royal Society of Edinburgh. Section B. Biological Sciences 96B: 181-201.

Hesp, P., 2002. "Foredunes and blowouts: initiation, geomorphology and dynamics." Geomorphology 48(1-3): 245-268

Hesp, P.A., T.A.G. Smyth, P. Nielsen, I.J. Walker, B.O. Bauer, and R.G. Davidson-Arnott, 2015. "Flow deflection over a foredune." Geomorphology 230: 64-74.

Hesp, P.A. and T.A.G. Smyth, 2017. "Nebkha flow dynamics and shadow dune formation." Geomorphology 282(C): 27-38.

Houser, C. and S. Mathew, 2011. "Alongshore variation in foredune height in response to transport potential and sediment supply: South Padre Island, Texas." Geomorphology 125(1): 62-72.

Jagschitz, J.A., and R.C. Wakefield, 1971. "How to Build and Save Beaches and Dunes." Kingston, RI: U. of Rhode Island Agricultural Experimental Station Bulletin 408.

Järvelä, J., 2002. "Flow resistance of flexible and stiff vegetation: a flume study with natural plants." J. Hydrology 269(1-2): 44-54.

Knutson, P.L., 1977. "Planting Guidelines for Dune Creation and Stabilization." CETA 77-74. U.S. Army Corps Engineering Coastal Research Center, Fort Belvoir, VA.

Leenders, J.K., G. Sterk, and J.H. Van Boxel, 2011. "Modelling wind-blown sediment transport around single vegetation elements." Earth Surface Processes \& Landforms 36: 1218-1229.

Maun, M.A. ,2009. The Biology of Coastal Sand Dunes. New York, NY: Oxford University Press.

Mendelssohn, I.A., M.W. Hester, and F.J. Monteferrante, 1991. "Experimental dune building and vegetative stabilization in a sand-deficient barrier island setting on the Louisiana coast, USA." J. Coastal Res. 7(1): 137-149.

Murray A.B., M.A. Knaapen, M. Tal, and M.L. Kirwan, 2008. "Biomorphodynamics: physicalbiological feedbacks that shape landscapes." Water Resources Research 44(11): W11301.

O'Connell, J., 2008. Coastal dune protection and restoration, using "Cape" American beachgrass and fencing. Woods Hole Sea Grant Consortium and Cape Cod Cooperative Extension, Woods Hole, MA

Ping, L., C. Narteau, Z. Dong, Z. Zhang, and S. Courrech du Pont, 2014. "Emergence of oblique dunes in a landscape-scale experiment." Nature Geoscience 7(12): 99-103.

R Core Team, 2017. R: A language and environment for statistical computing. R Foundation for Statistical Computing, Vienna, Austria. https://www.R-project.org/

Raupach, M.R., 1992. "Drag and drag partition on rough surfaces.” Boundary Layer Meteorology 60(4): 375-395.

Raupach, M. R., J.J. Finnigan, and Y. Brunet, 1996.
"Coherent eddies in vegetation canopies the mixing layer analogy." Boundary Layer Meteorology 78: 351-382.

Renken K.A., 2015. Investigations into ecogeomorphodynamics of coastal embryo dunes at Padre Island National Seashore, Texas. Louisiana State University Department of Geography and Anthropology, Ph.D. dissertation. 137 pgs.

Remondino, F., 2003. "From point cloud to surface the modeling and visualization problem." International Archives of the Photogrammetry, Remote Sensing and Spatial Information Sciences 34(5): W10.

Sarre, R.D., 1989. “The morphological significance of vegetation and relief on coastal foredune processes." Z Geomorph N F 73: 17-31.

Savage R.P. and W.W. Woodhouse Jr., 1968. "Creation and Stabilization of Coastal Barrier Dunes." Proc. of the 11th Conference on Coastal Engineering. ASCE, pp 671-700.

Seneca, E.D., W.W. Woodhouse Jr., and S.W. Broome, 1976. "Dune stabilization with Panicum amarum along the North Carolina coast." CERC Misc. Report 76-3. U.S. Army Corps of Engineers, Fort Belvoir, VA.

SICK Sensor Intelligence, 2017. “Trispector1000 3D Vision.” (https://sick-virginia.data.continum. net/media /docs/7/67/367/quickstart_TriSpector1000_3D_Vision_en_IM0060367.PDF) Accessed 12 February 2018.

Skaradek, W., C. Miller, and P. Hocker, 2003. Beachgrass Planting Guide for Municipalities and Volunteers. U.S. Department of Agriculture Cape May Plant Materials Center, Cape May, NJ.

Stallins, J.A., 2006. “Geomorphology and ecology: Unifying themes for complex systems in biogeomorphology." Geomorphology 77(34): 207-216.

Wolfe, S.A., and W.G. Nickling, 1996. "Shear stress partitioning in sparely vegetated desert canopies." Earth Surface Processes, \& Landforms 21: 607-619.

Wolner, C.W.V., L.J. Moore, D.R. Young, S.T. Brantley, S.N. Bissett, and R.A. McBride, 2013. "Ecomorphodynamic feedbacks and barrier island response to disturbance: Insights from the Virginia Barrier Islands, Mid-Atlantic Bight, USA." Geomorphology 199(C): 115-128.

Woodhouse, W.W., 1978 Dune building and stabili zation with vegetation. CERC, SR-3. U.S. Army Corps of Engineers. Fort Belvoir, VA.

Wootton, L., J. Miller, C. Miller, M. Peek, A. Williams, and P. Rowe, 2016. NJ Sea Grant Consortium Dune Manual. Sandy Hook, NJ: New Jersey Sea Grant Consortium.

Yagci, O., M.F. Celik, V. Kitsikoudis, V.S.O. Kirca, C. Hodoglu, M. Valyrakis, Z. Duran, and S. Kaya, 2016. "Scour patterns around isolated vegetation elements." Advances in Water Resources 97(C): 251-265.

Zarnetske, P.L., S.D. Hacker, E.W. Seabloom, P. Ruggiero, J.R. Killian, T.B. Maddux, and D. Cox 2012. "Biophysical feedback mediates effects of invasive grasses on coastal dune shape." Ecology 93(6): 1439-1450.

Zhang, W., R. Schneider, J. Kolb, T. Teichmann, J. Dudzinska-Nowak, J. Harff, and T.J.J. Hanebuth, 2015. "Land-sea interaction and morphogenesis of coastal foredunes - A modeling case study from the southern Baltic Sea coast." Coastal Engineering 99(C): 148-166. 